(⿶)

\title{
Virtual Laboratorium Teknik Digital berbasis Mobile Virtual Reality
}

\author{
Adhy Kurnia Triatmaja ${ }^{1 *}$, Muchlas ${ }^{2}$, Yoga Wardana ${ }^{3}$ \\ 1,2,3 Program Studi Pendidikan Vokasional Teknik Elektronika, Universitas Ahmad Dahlan \\ ${ }^{1}$ adhy.triatmaja@pvte.uad.ac.id* \\ *corresponding author
}

\begin{tabular}{|c|c|}
\hline ABSTRACT & Article Info \\
\hline $\begin{array}{l}\text { Virtual laboratory of digital engineering based mobile virtual reality is a } \\
\text { technology that will be change the conventional laboratory. The use of virtual } \\
\text { labs can be used for as long as you have an Android computer, wherever and } \\
\text { whenever. A technical breakthrough that makes virtual laboratories imitate } \\
\text { actual laboratories is the use of virtual reality technology. This thesis applies } \\
\text { mobile augmented reality technology to a virtual software engineering } \\
\text { laboratory. Until it becomes a functional product, many considerations and } \\
\text { processes are required in the application of a virtual laboratory. The results of } \\
\text { this study are used as materials for studying the application of virtual digital } \\
\text { engineering laboratories using mobile virtual reality technology. }\end{array}$ & $\begin{array}{r}\text { Article history } \\
\text { Received: Feb. } 11^{\text {th }}, 2021 \\
\text { Revised: May } 28^{\text {th }}, 2021 \\
\text { Accepted: May } 30^{\text {th }}, 2021 \\
\text { Keywords } \\
\text { digital engineering, } \\
\text { mobile virtual reality, } \\
\text { virtual laboratory. }\end{array}$ \\
\hline ABSTRAK & \\
\hline $\begin{array}{l}\text { Virtual laboratorium teknik digital berbasis mobile virtual reality merupakan } \\
\text { teknologi yang dapat dimanfaatkan sebagai pengganti laboratorium konvensional. } \\
\text { Penggunaan virtual laboratorium dapat digunakan dimanapun dan kapanpun } \\
\text { selama memiliki perangkat android. Penggunaan teknologi virtual reality } \\
\text { merupakan suatu perkembangan teknologi sehingga membuat virtual } \\
\text { laboratorium dapat menyerupai laboratorium yang sebenarnya. Penelitian ini } \\
\text { mengaplikasikan virtual laboratorium teknik digital dengan teknologi mobile } \\
\text { virtual reality. Dalam mengaplikasikan virtual laboratorium perlu beberapa } \\
\text { pertimbangan dan proses yang harus dilakukan sebelum menjadi suatu produk } \\
\text { yang dapat digunakan. Hasil dari penelitian ini adalah sebagai bahan untuk } \\
\text { mempelajari dalam mengaplikasikan virtual laboratorium teknik digital dengan } \\
\text { menggunakan teknologi mobile virtual reality. }\end{array}$ & \\
\hline
\end{tabular}

\section{PENDAHULUAN}

Laboratorium yang dapat digunakan sebagai sarana latihan praktik oleh peserta didik pada suatu instansi pendidikan. Pembangunan laboratorium membutuhkan suatu perencanaan yang matang dan memerlukan dana yang besar. Kebutuhan suatu laboratorium berbeda-beda sesuai dengan fungsi dari laboratorium itu dibuat.
Laboratorium yang telah ditetapkan fungsi akan menjadi permanen dan akan membutuhkan waktu yang lama untuk merombak suatu fungsi dari laboratorium.

Laboratorium harus memiliki aturan penggunaan setiap alat dan keamanan yang harus diawasi secara berkala. Kecelakaan kerja yang terjadi pada laboratorium dapat mengganggu penggunaan dari laboratorium saat digunakan. Perbaikan pada laboratorium 
dan alat yang terdapat pada laboratorium membutuhkan waktu yang cukup lama. Beberapa peralatan laboratorium juga harus diganti dan tidak bisa diperbaiki apabila terdapat kerusakan tertentu, sehingga perlu pengadaan ulang pada peralatan laboratorium yang ada.

Smartphone pada era sekarang ini merupakan kebutuhan utama yang harus dimiliki setiap orang. Kebutuhan smartphone juga membantu dalam berkomunikasi dan berinteraksi kapan saja tanpa ada halangan jarak. Operating System (OS) yang banyak digunakan pada perangkat smartphone adalah Android. OS android juga didukung dengan banyak aplikasi yang dapat digunakan secara gratis. besar pengembang juga membuat aplikasi pada OS android karena lebih banyak digunakan di semua kalangan.

Salah satu teknologi yang dapat digunakan di masa depan pada android adalah Virtual Reality (VR). Penggunaan virtual reality sudah banyak digunakan pada perangkat game dengan didukung dengan kacamata Virtual Reality dan pengenkendali Virtual Reality. Teknologi Virtual Reality merupakan teknologi dimana suatu perangkat dapat menampilkan suatu bentuk visual yang terlihat seperti kenyataan. Penggunaan Virtual Reality pada laboratorium dapat meningkatkan keamanan dan kemudahan dalam pengadaan fasilitas dari laboratorium.

Teknik digital merupakan kompetensi yang baik untuk dimiliki untuk menghadapi era industri 4.0. sebagian besar komponen utama yang digunakan pada era industri tersebut adalah menggunakan data digital dan komunikasi antar mesin. Pengetahuan tentang teknik digital merupakan dasar dari pemrograman dan pengembangan dari mesinmesin yang terdapat pada era tersebut.

Salah satu model dari laboratorium yang saat ini sering digunakan adalah remote laboratorium. remote laboratorium juga dikenal dengan nama online laboratorium. Salah satu online laboratorium pada teknik elektro adalah laboratorium elektronika.
Dimana online laboratorium memberikan pengetahuan kepada peserta didik dengan konsep dan kemampuan secara teknis dengan praktik dengan waktu lebih lama menggunakan online laboratorium (Almarshoud, 2011: 1617). keunggulan tersebut mirip dengan penggunaan virtual laboratorium yang dapat digunakan kapan saja dan dimana saja. Tetapi pada laboratorium konvensional dapat memberikan kemampuan untuk mengatasi masalah dan kemampuan kerja sama pada peserta didik.

Karakteristik dari manajemen laboratorium harus memiliki lima acuan, yaitu: simple, measurable, achievable, relevant, dan time bound (SMART). SMART dibutuhkan pada pengembangan dan pengaplikasian virtual laboratorium (Mekonnen, 2004: 17) karena manajemen laboratorium dapat meningkatkan kualitas dari virtual laboratorium. Kualitas dari laboratorium didefinisikan sebagai akurasi, reliabel, dan hasil tes yang berkelanjutan (WHO, 2011: 21).

Dua belas kualitas sistem dari manajemen laboratorium, itu adalah organization, personil, equipment, purchasing and inventory, process control, information management, document and record, occurrence management, assessment, process improvement, customer service, serta facilities and safety. Dua belas sistem tersebut dapat digunakan pada pengembangan dan pengaplikasian dari virtual laboratorium untuk mengetahui kualitas laboratorium (WHO, 2011: 18-19).

Sistem manajemen keamanan pada laboratorium harus diawasi sesuai dengan standar dari keamanan laboratorium dan menyiapkan untuk kebutuhan darurat. Pada laboratorium konvensional dibutuhkan teknisi yang selalu menjaga keamanan pada laboratorium. Kemanan pada laboratorium merupakan hal yang sangat penting yang harus dijaga agar penggunaan laboratorium menjadi lebih efektif (Bureau, 2013: 2).

Teknologi mobile yang digunakan pada mobile learning. Konsep dari mobile 
learning memiliki lima karakteristik, hal tersebut adalah probabilitas, aksesibilitas, personalisasi, konektivitas, dan dapat meningkatkan motivasi belajar. Karakteristik tersebut mirip dengan karakteristik pada virtual laboratorium karena penggunaan virtual laboratorium yang diterapkan juga berbasis pada mobile (Persson \& Nouri, 2018: 191).

Virtual Reality didefinisikan sebagai simulasi komputer dari lingkungan 3D dimana pengguna dapat berinteraksi dengan melihat benda fisik seperti pada kenyataan dengan menggunakan peralatan khusus, seperti helm dengan layar di bagian dalam dan sarung tangan yang terdapat sensor. Terdapat beberapa kategori dari VR yaitu desktop VR, Immersive $\mathrm{VR}$, distributed $\mathrm{VR}$, dan augmented VR (Zhang et al, 2018: 138).

Keunggulan dari virtual laboratorium yaitu mudah digunakan, mudah untuk mengerti konsep teori, tersedia waktu yang banyak, memuaskan pada teori pengetahuan, lingkungan yang aman, kemajuan keahlian baru, didorong dengan kerja sama kelompok, tempat yang nyaman, waktu bereksperimen lebih banyak (Odeh, 2015: 7-8).

Terdapat enam karakteristik yang harus diikuti pada penyusunan virtual laboratorium yang meliputi: 1) karakteristik fisik dari peralatan virtual laboratorium harus konsisten dengan peralatan pada laboratorium dunia nyata; 2) kemampuan menjadi pembelajaran yang interaktif yang lebih tinggi; 3) kemampuan untuk memberikan umpan balik secara real-time; 4) fungsi dalam penggunakan alat; 5) tampilan virtual mirip dengan lingkungan yang sebenarnya; serta 6) tampilan virtual merupakan pemandangan yang dapat diubah sesuai dengan kebutuhan seperti mengurangi, memperbesar, dan menjelajah (Lixia, 2009: 629).

Keunggulan dari virtual reality yang dimanfaatkan sebagai virtual laboratorium yang meliputi lingkungan virtual dapat menghemat anggaran daripada lingkungan fisik, lingkungan virtual lebih aman dibandingkan dengan lingkungan fisik, interaksi melalui lingkungan virtual memberikan pengalaman tertentu yang tidak didapat pada lingkungan fisik, praktik pada lingkungan virtual dapat lebih dikembangkan daripada lingkungan fisik, konsep pembelajaran dari pengalaman yang dialami pengguna secara langsung, lingkungan virtual memberikan kesan yang nyata menyerupai lingkungan fisik (Jaya, 2010: 1). Virtual laboratorium dapat meningkatkan motivasi siswa dalam hal nilai tugas dan kemanjuran diri (Dyrberg, 2016: 13).

Keuntungan dari penggunaan emulator pada teknik digital, yaitu: tampilan asli nuansa dan perilaku objek digital dipertahankan, modal awal pada produksi emulator lebih besar tetapi pengeluaran lain akan lebih efisiensi, mengurangi waktu penggunaan laboratorium, banyak emulator yang sudah dikembangkan dengan baik dan berlisensi, emulator dapat digunakan di berbagai sistem perangkat, kebutuhan fisik dari emulator dapat dikurangi sehingga dapat mengurangi biaya dan waktu praktik, kebanyakan emulator memiliki memori data yang besar dan dapat menyediakan banyak komponen elektronik yang disimulasikan (Ogungbenro et al, 2017: 657).

\section{METODE}

\section{Konsep Virtual Laboratorium}

Virtual laboratorium yang akan dibuat menggunakan teknologi mobile Virtual Reality. Virtual laboratorium dibuat menyerupai laboratorium konvensional yang sebenarnya. Kendali dari pergerakan virtual laboratorium menggunakan remote bluetooth yang diatur agar dapat menjalankan perintah-perintah pada virtual laboratorium. Pada virtual laboratorium terdapat beberapa pilihan yang dapat dikerjakan oleh pengguna. Seperti mengetahui dasar-dasar teori dari gerbang logika. Kemudian terdapat juga simulasi dari gerbang logika dan simulasi rangkaian gerbang logika. 


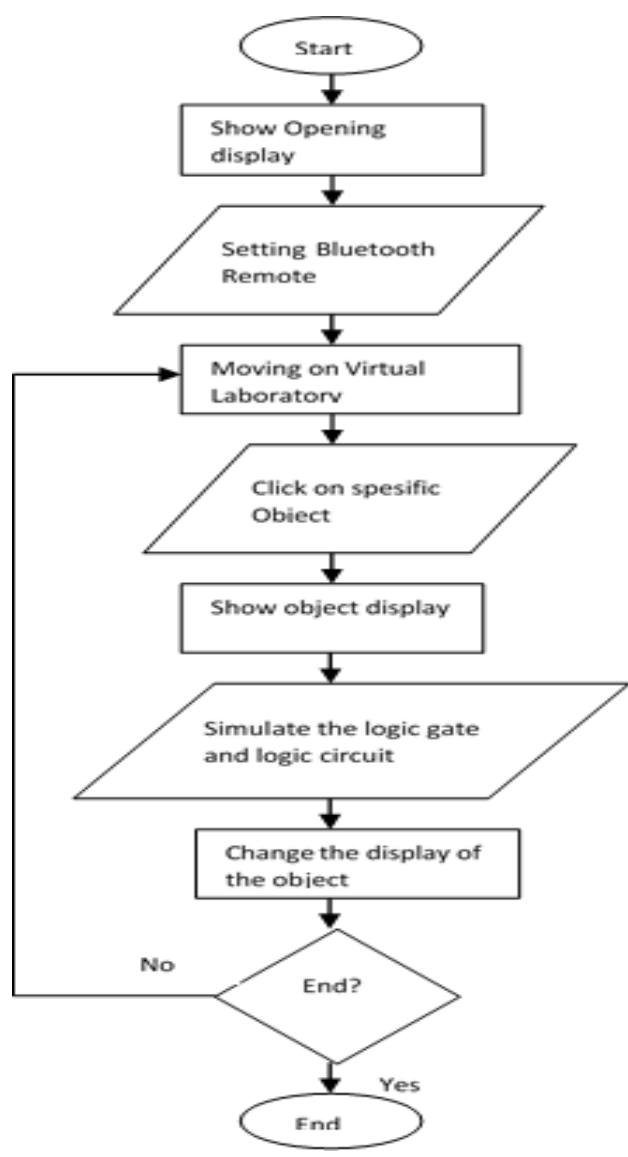

Gambar 1. Flowchart Virtual Laboratorium

Pada Gambar 1, flowchart dijelaskan bahwa ketika virtual laboratorium teknik digital dijalankan maka akan muncul tampilan pembuka yang menunjukan hal pertama yang dapat dilakukan pada virtual laboratorium. Pada tampilan pertama tersebut, akan ada tampilan berbentuk kotak bertuliskan perintah awal dalam penggunaan virtual laboratorium. Kalimat pada tampilan tersebut berupa perintah untuk bergerak menuju daerah tertentu dan memulai menggunakan virtual laboratorium. Perintah pertama adalah untuk bergerak menuju pojokan ruangan dan mengklik bagian IC agar muncul tampilan dan perintah-perintah tertentu. Tujuan dari perintah tersebut adalah untuk membuat pengguna dapat beradaptasi dengan virtual laboratorium teknik digital sehingga akan mudah dalam mengoperasikan aplikasi virtual laboratorium teknik digital tersebut.

Pada flowchart bagian kedua setelah muncul tampilan utama, pengguna belum dapat menggunakan perintah untuk berjalan pada virtual laboratorium teknik digital. Pengguna diminta untuk mengatur dahulu remote bluetooth yang sudah disediakan. Terdapat beberapa tahapan dalam mengatur remote bluetooth. Pertama dalam menngatur remote bluetooth adalan dengan mengaktifkan dahulu remote bluetooth yang disediakan dengan memberikan baterai dan menekan tombol power dengan lama. Ketika proses ini indikator lampu pada remote bluetooth akan menyala secara berkedip yang menunjukan bahwa remote bluetooth sedang menunggu untuk dikoneksikan pada perangkat android. Langkah selanjutnya yang harus diatur adalah bluetooth pada perangkat android, hal tersebut dilakukan dengan cara mengaktifkan bluetooth pada android dan melakukan pemasangan dari perangkat android menuju perangkat remote bluetooth.

Setelah melakukan tahap pemasangan pada remote bluetooth maka lampu indikator pada remote bluetooth yang sebelumnya menyala secara berkedip akan mati yang menunjukan bahwa remote bluetooth sudah siap untuk dipakai. Pada tahap ini remote bluetooth sudah terkoneksi namun belum dapat digunakan untuk berjalan pada virtual laboratorium teknik digital. Diperlukan kalibrasi pada remote bluetooth untuk mengubah mode dari remote bluetooth agar pengguna dapat bergerak pada virtual laboratorium. Kalibrasi tersebut dilakukan dengan menekan tombol @+ C. Setelah menekan tombol tersebut perangkat remote bluetooth dapat terkoneksi dengan perangkat android dan dapat digunakan untuk bergerak pada virtual laboratorium teknik digital. Ciri bahwa remote bluetooth sudah terkalibrasi dan siap digunakan pada virtual laboratorium teknik digital adalah muncul tampulan cursor ketika arah analog pada remote bluetooth digerakkan.

Setelah rangkaian kalibrasi pada remote bluetooth selesai, maka pengguna dapat berjalan atau bergerak pada virtual laboratorium teknik digital. Pengguna ketika memakai mode virtual laboratorium apabila pengguna menggerakan tombol analog pada 
remote bluetooth maka pengguna akan dapat bergerak sesuai arah tombol remote bluetooth ketika diarahkan ke arah tertentu. Dalam bergerak pengguna tidak dapat melewati bendabenda padat yang ada pada virtual laboratorium teknik digital. Hal tersebut disesuaikan dengan karakteristik benda pada dunia nyata.

Tahap selanjutnya dari flowchart adalah pengguna dapat memberikan perintah pada benda tertentu pada virtual laboratorium teknik digital. Perintah yang diberikan akan muncul ketika melakukan klik pada remote bluetooth atau ketika layar ditekan. Ciri dari benda pada virtual laboratorium teknik digital memiliki suatu perintah tertentu adalah ketika benda tersebut berada di titik tengah maka titik tengah tersebut akan berubah menjadi lingkaran yang menunjukan bahwa benda tersebut siap diberikan perintah sehingga dapat memunculkan tampilan tertentu. Terdapat beberapa benda yang dapat diperintah pada virtual laboratorium teknik digital, benda tersebut antara lain, IC yang dapat memunculkan sifat-sifat dan karakteristik dari gerbang logika, Laptop yang mampu memunculkan tampilan simulasi dari setiap gerbang logika tertentu sesuai pada perintah di laptop, dan komputer yang memberikan simulasi pada rangkaian gerbang logika yang lebih kompleks berdasarkan aljabar Boolean.

Pada tahap simulasi, dapat dimunculkan ketika memberikan perintah pada laptop atau komputer pada virtual laboratorium teknik digital. Simulasi yang dapat dilakukan adalah berupa simulasi gerbang logika dengan cara memberikan masukan antara 0 atau 1 dan otomatis keluaran akan muncul sesuai logika dari gerbang logika tersebut. Selain simulasi gerbang logika, pada komputer-komputer di setiap meja memiliki berbagai macam jenis rangkaian gerbang logika yang lebih kompleks dengan sistem kerja yang sama dengan simulasi gerbang logika, yaitu memberikan masukan pada rangkaian tersebut sehingga dapat memunculkan hasil tertentu sesuai logika dan kebenaran dari rangkaian gerbang logika tersebut.
Tahap selanjutnya sebelum tahap terakhir adalah pengguna diberikan keleluasaan untuk mengubah tampikan atau masukan dari simulasi yang terdapat pada virtual laboratorium teknik digital dengan cara menekan tombol pada remote bluetooth sehingga dapat mengubah masukan pada semua simulasi menjadi 0 atau 1. Pengguna juga dapat mengganti simulasi gerbang logika yang ada ketika melakukan simulasi gerbang logika. Simulasi gerbang logika yang dapat diganti adalah AND dengan OR, kemudian NAND dengan NOR. Ketika selesai dalam menggunakan virtual laboratorium teknik digital pengguna hanya menekan tombol close atau back pada layar smartphone dan apabila pengguna masih ingin menggunakan virtual laboratorium teknik digital maka pengguna hanya tinggal mengeksplorasi pada bagianbagian virtual laboratorium yang belum dicoba.

Hal tersebut merupakan tahapan dalam pengembangan virtual laboratorium teknik digital. Penggunaan virtual laboratorium dengan berdasarkan tahapan tersebut diperlukan waktu tertentu dan persiapan tertentu untuk dapat menggunakannya pada tingkat suatu lembaga atau sekolah. Virtual laboratorium juga membutuhkan peralatan pendukung untuk mendukung virtual laboratorium teknik digital dapat diaplikasikan dengan baik dan sesuai dengan standar dan ketentuan serta kesesuaian pada materi-materi pembelajaran tertentu.

\section{Tampilan Virtual Laboratorium}

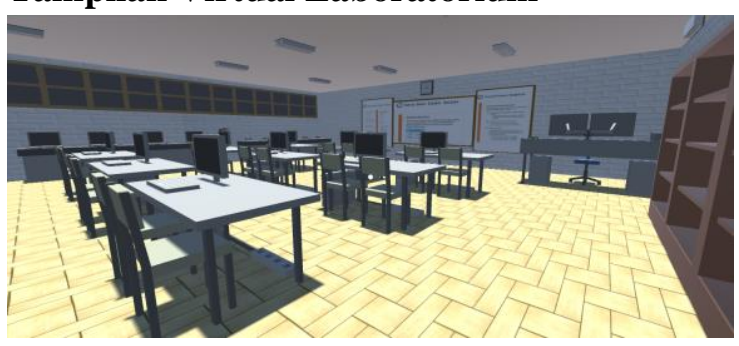

Gambar 2. Tampilan Ruang Virtual laboratorium

Gambar 2 menunjukan tampilan ruang dari virtual laboratorium teknik digital. Terdapat berbagai benda yang dapat digunakan 
secara aplikatif dan dapat menampilkan tampilan lain seperti simulasi dari gerbang logika pada teknik digital. Dalam virtual laboratorium didesain dan dikembangkan agar menyerupai benda nyata. Dalam virtual laboratorium memiliki banyak komponen benda seperti keramik, meja, kursi, komputer, laptop, papan tulis, IC, hingga lampu sehingga ketika pengguna menggunakan virtual laboratorium teknik digital, maka pengguna diberikan pemandangan yang sama dengan pemandangan di dunia nyata. Benda-benda pada virtual laboratorium memiliki karakteristik dan sifat yang sama dengan benda pada dunia nyata, seperti meja kursi yang memiliki sifat keras dan tidak mudah dilewati, sehingga pada virtual laboratorium bendabenda tersebut juga tidak dapat dilewati dan tidak tembus ketika pengguna bergerak ke arah tertentu melewati benda tersebut.

Pada virtual laboratorium teknik digital juga memiliki pencahayaan yang cukup untuk melakukan praktek seperti pada laboratorium konvensional. Terdapat juga bayangan dari benda sehingga benda-benda tersebut terlihat seperti nyata dan benda-benda tersebut juga memiliki sifat yang sama pada dunia nyata. Tata letak benda pada virtual laboratorium juga disesuaikan dengan ergonomis yang sesuai standar K3 sehingga pengguna dapat mengetahui bagaimana tata letak yang seharusnya pada suatu laboratorium teknik digital. Dalam virtual laboratorium teknik digital juga terdapat tampilan awal yang memberikan kita perintah untuk hal yang dapat dilakukan pertama kali. Perintah tersebut dapat dilihat pada Gambar 3.

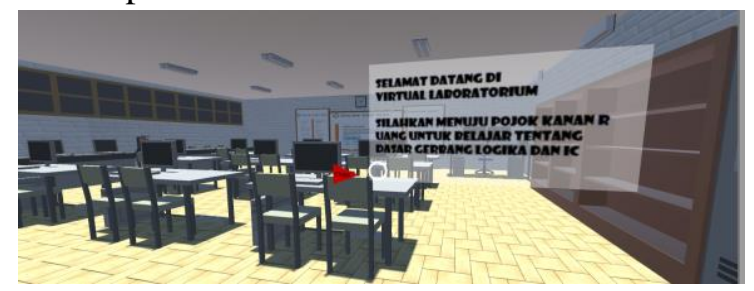

Gambar 3. Tampilan awal pada virtual laboratorium
Virtual laboratorium juga memiliki tampilan dengan bentuk mirip dengan bendabenda dunia nyata namun masih terlihat seperti benda visual. Penggunaan virtual laboratorium teknik digital disesuaikan dengan standar laboratorium yang dipakai di dunia nyata. Penggunaan virtual laboratorium teknik digital juga digunakan sebagai upaya menghemat pembangunan suatu laboratorium asli karena dalam virtual laboratorium penambahan komponen atau peralatan pada virtual laboratorium dapat dilakukan dengan cepat dan tanpa harus mengeluarkan tambahan. Penambahan peralatan pada virtual laboratorium teknik digital dilakukan dengan mendesain bentuk virtual dari benda-benda dari dunia nyata yang kemudian diubah dalam bentuk virtual dan bentuk 3D. Setelah bentuk benda asli diubah menjadi 3D dalam bentuk visual, dilakukan pewarnaan yang disesuaikan dengan warna benda pada dunia nyata. Hal tersebut dilakukan agar mendapat bentuk virtual yang memiliki kemiripan dengan benda nyata.

Setelah tahap desain benda nyata menjadi benda virtual selesai, benda-benda tersebut dapat dimasukkan pada virtual laboratorium teknik digital sebagai salah satu peralatan yang dapat digunakan dan dimanfaatkan pada virtual laboratorium. Benda-benda yang dimasukkan pada virtual laboratorium memiliki fungsi-fungsi tertentu yang dapat memberikan kesan dan fungsi yang sama pada benda-benda yang terdapat pada dunia nyata. Pencahayaan pada virtual laboratorium terpasang di atas. Hal ini diumpamakan sebagai sebuah lampu yang menerangi laboratorium di dunia nyata. Lampu pada virtual laboratorium teknik digital ini dapat menghasilkan bayangan bada bendabenda padat di sekitar sesuai dengan posisi lampu tersebut. Terdapat juga beberapa lemari dan rak yang nantinya dapat dikembangkan dengan berbagai peralatan yang dapat mendukung proses praktik pada virtual laboratorium teknik digital. 


\section{HASIL DAN PEMBAHASAN}

\section{Peralatan dan Perangkat Virtual \\ Laboratorium}

Peralatan yang digunakan untuk pengembangan dan pengimplementasian pada virtual laboratorium adalah:

- VR box

- VR Controller

- Android Smartphone (Xiaomi Redmi 4X)

- Laptop

- Unity3D

- Virtual Laboratorium.apk

Virtual laboratorium dikembangkan menggunakan aplikasi Unity3D pang dikerjakan dengan laptop. Virtual laboratorium menggunakan teknologi virtual reality yang berjalan pada perangkat android smartphone. Aplikasi yang dihasilkan dari pemrograman pada Unity3D adalah Virtual Laboratorium.apk peralatan pendukung dari virtual laboratorium adalah VR box yang dipasang seperti menggunakan kacamata dan VR Controller yang digunakan sebagai penggerak ketika menjalankan virtual laboratorium. Berikut adalah bentuk VR box dan VR Controller pada Gambar 4.

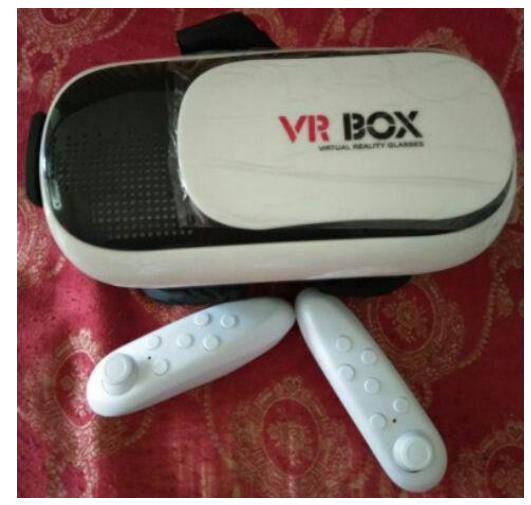

Gambar 4. VR box dan VR controller

Peralatan pada virtual laboratorium teknik digital ini disesuaikan dengan kebutuhan dan peralatan dari kebutuhan laboratorium di dunia nyata. Penggunaan VR Box dapat mendukung bentuk dari virtual laboratorium sehingga dapat menghasilkan kesan nyata pada virtual laboratorium teknik digital. Dalam menggunakan VR Box, pengguna hanya perlu menggerakkan kepala untuk mengetahui sekeliling dari virtual laboratorium. Hal tersebut juga harus didukung dengan perangkat android yang sesuai dan memiliki sensor posisi. Sensor posisi pada perangkat android digunakan untuk mengetahui posisi arah kepala sehingga seakan penglihatan kita dapat berubah sesuai arah mata yang kita tuju.

Peralatan tersebut juga harus didukung dengan peralatan untuk bergerak ke tempattempat tertentu pada virtual laboratorium teknik digital. Pergerakan tersebut dapat dilakukan menggunakan remote bluetooth dengan spesifikasi remote satu tangan dengan menggunakan komunikasi bluetooth yang dapat mengendalikan layar perangkat smartphone dan aplikasi virtual laboratorium teknik digital. Dalam remote bluetooth tersebut memiliki 2 tombol di depan yang berfungsi sebagai tombol OK dan Cancel pada perangkat smartphone. Terdapat juga tombol analog yang dapat diarahkan $360^{\circ}$ yang difungsikan sebagai penggerak dari karakter utama atau karakter yang dilihat menuju ke tempat-tempat tertentu.

Terdapat enam tombol lain yang masing-masing memiliki fungsi yang berbeda. Satu tombol berfungsi sebagai tombol power dari virtual laboratorium teknik digital, tombol satu lagi digunakan sebagai pengubah mode dari remote, tombol ini berbentuk @. Terdapat juga empat tombol lain yang memiliki fungsi yang berbeda-beda. Setiap tombol memiliki mode tersendiri apabila ditekan bersamaan dengan tombol @. Masing-masing fungsi tombol tersebut adalah pada tombol A digunakan untuk mengubah remote menjadi penggerak pada VR dengan kendali horizontal, tombol B digunakan untuk mengeubah remote bluetooth menjadi pengubah suara dan kamera. Tombol $\mathrm{C}$ berfungsi sebagai kendali dari virtual laboratorium dengan kendali vertical. Dan tombol D akan memunculkan cursor seperti cursor mouse yang dapat digunakan selayaknya menggunakan mouse. 


\section{Gesture pada Virtual Laboratorium}

Beberapa gerakan yang dapat dilakukan pada virtual laboratorium antara lain:

- Kendali Penggerak - digunakan untuk menggerakkan seolah pengguna berjalan ke berbagai arah. Kendali penggerak menggunakan fungsi tombol pada VR controller. Tombol yang digunakan untuk menggerakkan adalah mouse pad pada VR controller. Program yang digunakan dapat dilihat pada Gambar 5.

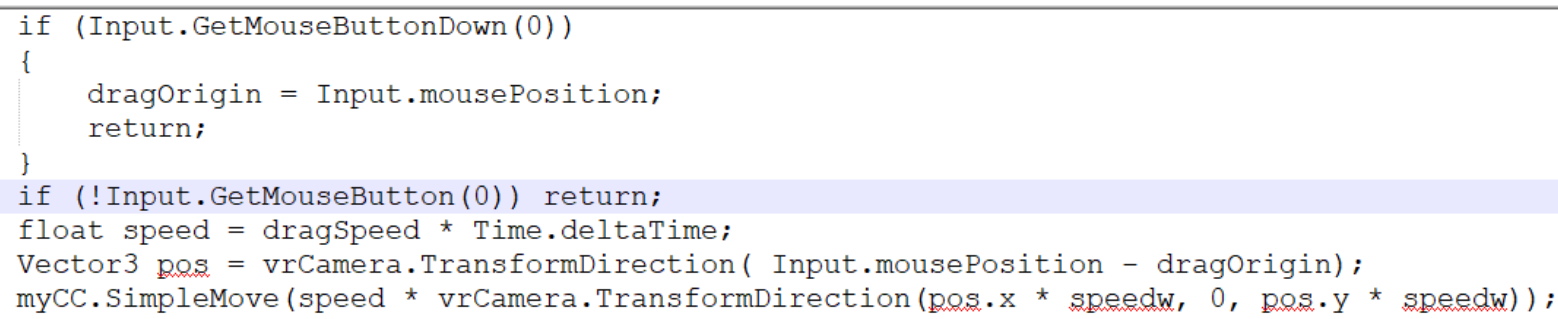

Gambar 5. Program Penggerak dengan Remote Bluetooth

Pada Kendali penggerak pembacaan program dilakukan dengan mendeteksi nilai analog pada remote bluetooth dan mengubah tampilan pada virtual laboratorium sehingga menunjukan seakan dapat bergerak ke tempat tertentu. Kemampuan mendeteksi nilai analog pada remote bluetooth dapat dibaca dengan menggunakan komunikasi bluetooth yang ada dan membaca nilai analog bluetooth ke atas atau ke bawah dengan berbedaan nilai positif dan negatif. Pembacaan arah berdasarkan nilai analog yang dikirimkan pada remote bluetooth. Berikut Gambar 6 adalah flowchart penggunaan remote bluetooth sebagai penggerak pada virtual laboratorium.

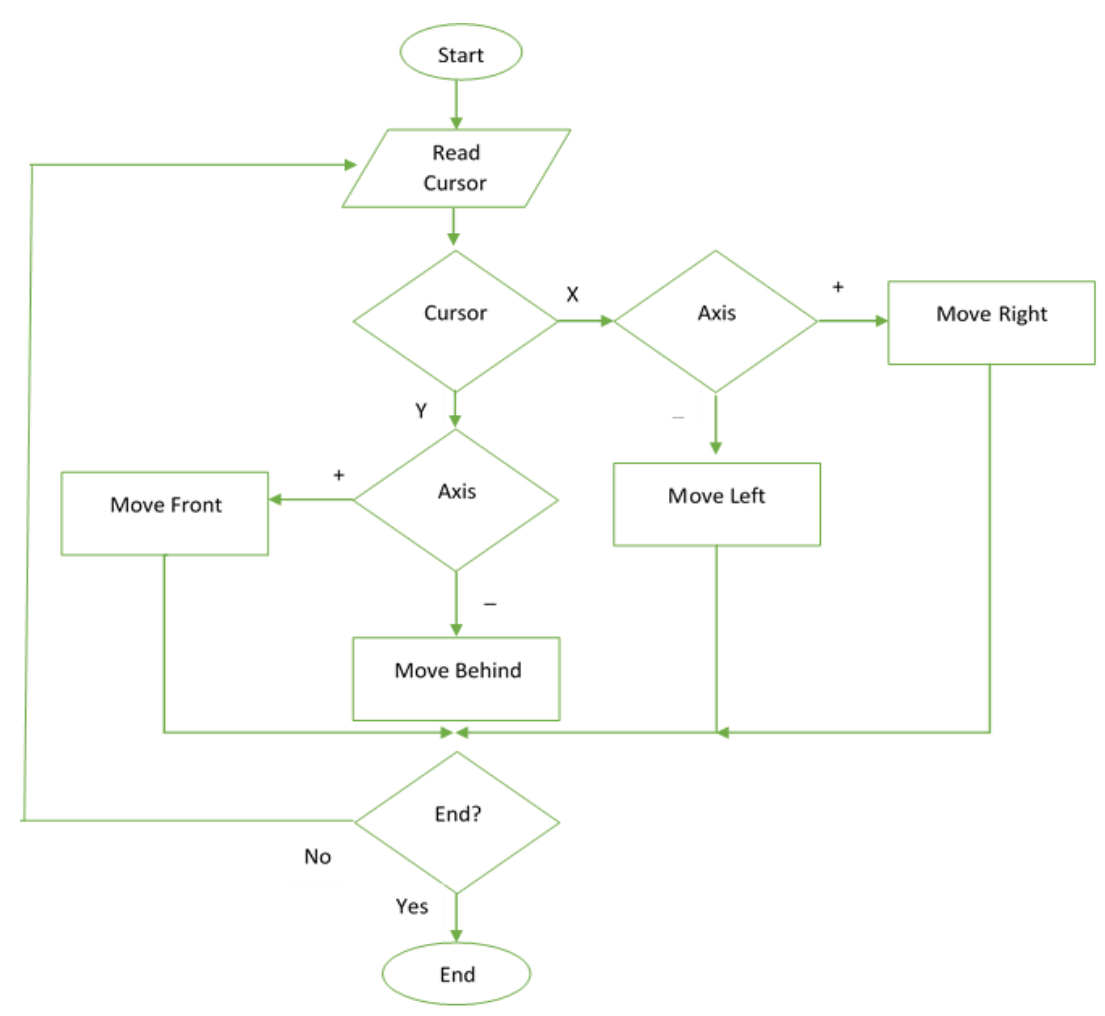

Gambar 6. Flowchart Penggunaan Kendali Penggerak

Sistem kerja pada kendali penggerak adalah dimulai dari membaca nilai cursor pada remote bluetooth. Untuk membaca data dari remote bluetooth diharuskan untuk 
menyambungkan koneksi antara remote bluetooth dan android terlebih dahulu. Kemudian apabila sudah memasuki aplikasi, gerakan tombol kursor akan dapat digerakkan dan akan diikuti oleh gerakan pada virtual laboratorium. Setiap gerakan kursor pada bluetooth remote dibagi menjadi dua arah, yaitu $\mathrm{X}$ dan $\mathrm{Y}$. Masing-masing arah memiliki nilai tertentu yang memiliki nilai diatas 0 dan dibawah 0. Nilai tersebut yang menentukan gerakan maju atau mundur atau gerakan kanan kiri agar sesuai dengan kursor. Gerakan pada kursor tersebut mengubah nilai koordinat dari posisi awal sehingga gerakan pada virtual laboratorium mengikuti arah dari gerakan kursor.

Apabila pembacaan pada remote bluetooth cursor $\mathrm{ke}$ atas maka akan memberikan nilai $\mathrm{Y}+$ sehingga memerintahkan koordinat penglihatan akan bergerak maju ke depan, dan sebaliknya apabila remote bluetooth diarahkan ke bawah maka nilai Y - pada remote akan memberikan perintah pada virtual laboratorium untuk mundur ke belakang. Sedangkan untuk kanan kiri pada remote bluetooth dapat menggerakkan arah kanan dan kiri pada remote bluetooth akan memberikan nilai $X+$ atau $X-$ sehingga akan mengubah koordinat dari tampilan menuju ke kanan atau ke kiri.

- Kendali Visual - Untuk menggerakkan visual sesuai arah mata dalam melihat. Pada kendali visual penglihatan digerakkan sesuai posisi kepala arah kita menghadap. Kendali visual membaca nilai sensor gyro dan accelerometer pada perangkat android. Pemrograman pada Unity3D memiliki fitur agar menggantikan gerakan penglihatan menjadi dengan pembacaan sensor gyro pada android. Fitur tersebut akan ditampilkan pada Gambar 8. Berikut Gambar 7 adalah program yang digunakan sebagai kendali visual dari virtual laboratorium.

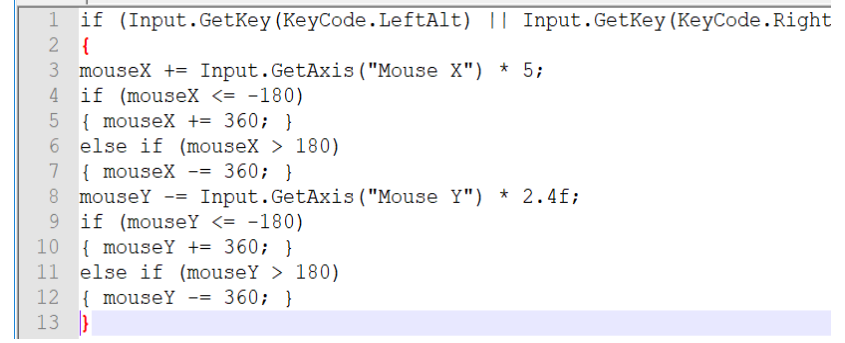

Gambar 7. Program Kendali Arah Pandangan

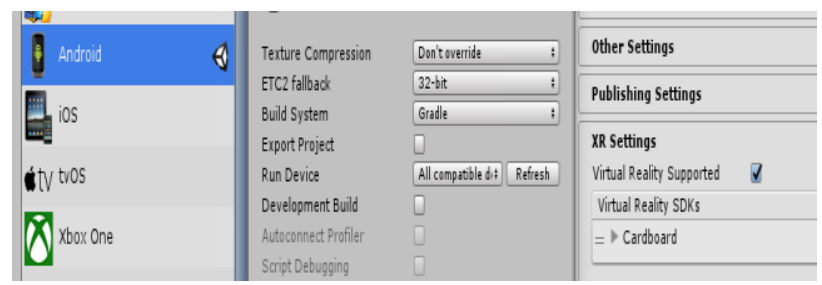

Gambar 8. Setting Kendali Visual pada

Unity3D

Pada pemrograman kendali visual menggunakan perintah pada mouse untuk mengetahui arah pandangan. Pada aplikasi Unity3D terdapat fitur untuk menjadikan suatu aplikasi menjadi virtual reality. Hal tersebut dapat mengubah gerakan mouse menjadi gerakan android dengan membaca sensor gyro. Pembacaan sensor gyro pada android akan otomatis dibaca ketika program dibuka, dengan cara mengaktifkan virtual reality supported ketika melakukan compile. Maka aplikasi yang terdapat pada android akan terdeteksi sebagai aplikasi virtual reality sehingga otomatis akan menggunakan sensor gyro untuk mendeteksi gerakan yang disesuaikan dengan gerakan pada virtual laboratorium.

Pada kendali visual, pemrograman hampir sama dengan kendali penggerak. Yang membedakan adalah data yang dibaca pada virtual laboratorium yang pada penggerak merupakan data dari cursor pada remote bluetooth yang digerakkan ke atas kanan kiri atau bawah. Sedangkan pada kendali visual, data yang dibaca adalah sensor gyro pada perangkat android yang mendeteksi gerakan kepala ketika melihat ke berbagai arah. Sistem kerja dari kendali visual dapat dilihat pada Gambar 9. 


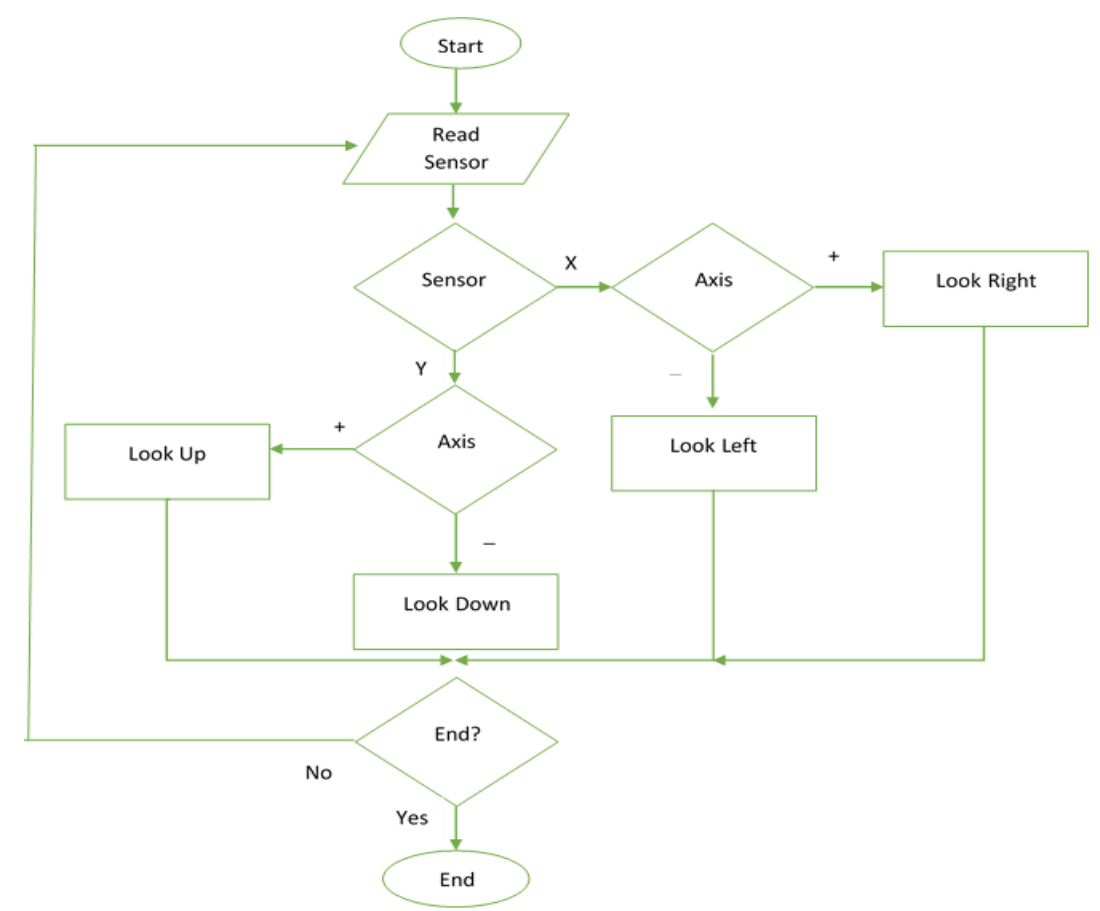

Gambar 9. Flowchart Kendali Visual

- Kendali Perintah - untuk membuka/melihat/ mengaktifkan suatu perintah sesuai benda tertentu dan perintah tertentu. Untuk mengendalikan perintah pada virtual laboratorium, patokan utama terdapat pada titik tengah pada layar atau pandangan pengguna. Perintah diberikan dengan cara menekan tombol ok pada remote dengan arahan navigasi dari titip tengah layar. Pada virtual laboratorium beberapa benda yang dapat diberikan perintah ditunjukkan dengan perubahan titik tengah pada layar menjadi sebuah lingkaran. Pada Gambar 10 ditunjukkan perubahan pada titik tengah layar yang menunjukkan bahwa suatu benda pada virtual laboratorium dapat diberikan perintah. Berikut adalah program yang digunakan untuk memberikan perintah melalui titik tengah layar atau pandangan.

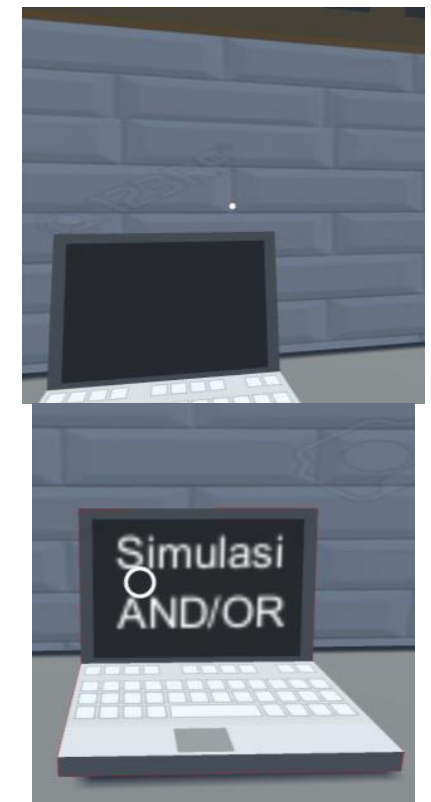

Gambar 10. Perubahan Titik yang Menunjuk

Pada kendali perintah, beberapa benda yang dapat diperintah dapat diketahui dengan perubahan titik tengah pada tampilan pandangan. Benda-benda tersebut adalah IC dan komputer yang terdapat pada meja beberapa benda menampilkan tampilan berupa keterangan dan karakteristik IC pada benda dengan bentuk IC pada Gambar 11. Simulasi dari penggunaan IC dapat dilihat pada Gambar 
12 dan simulasi rangkaian digital dapat dilihat pada Gambar 13.

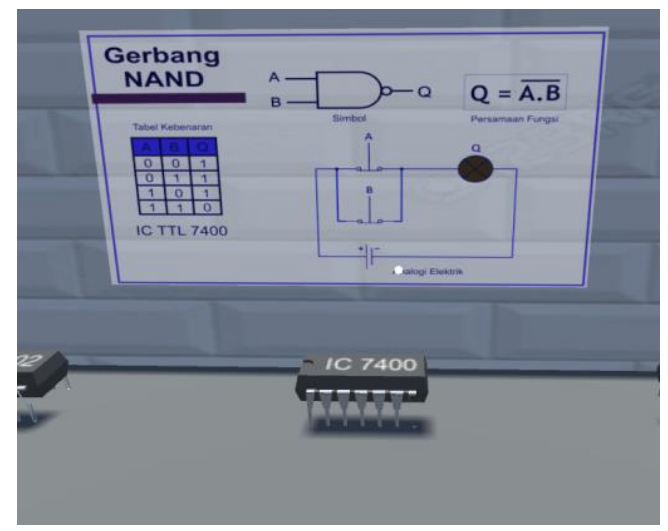

Gambar 11. Tampilan perintah karakteristik gerbang IC

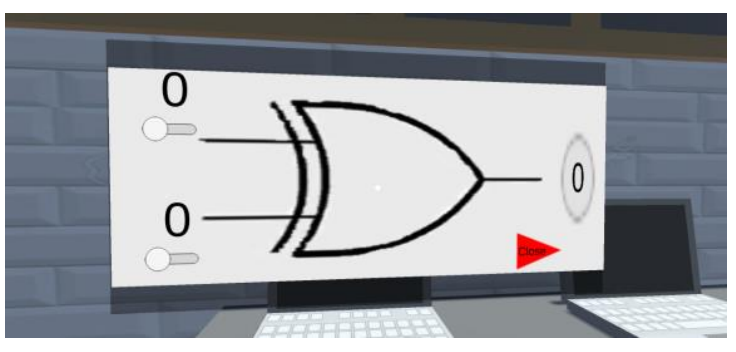

Gambar 12. Tampilan perintah simulator gerbang IC

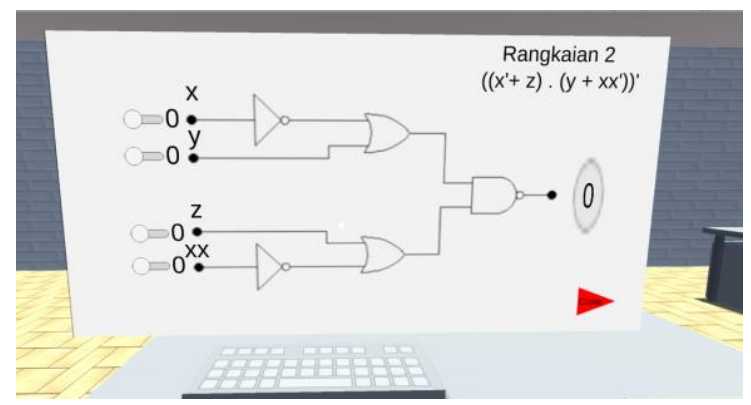

Gambar 13. Tampilan perintah simulator rangkaian digital

Pada bentuk IC terdapat beberapa pilihan IC pada tampilan virtual reality. IC tersebut merupakan IC AND, OR, NAND, NOR, XOR, dan NOT. IC tersebut menampilkan keterangan dari sifat gerbang IC, simbol gerbang IC dan rangkaian pada penggunaan gerbang IC. Selain untuk untuk menampilkan tampilan tersebut perlu ditekan pada IC yang digunakan dan untuk menghidangkannya perlu di tekan kembali pada IC yang ditekan sebelumnya. Program yang digunakan untuk menampilkan dan menghilangkan adalah program yang berfungsi untuk menghilangkan dan memunculkan tampilan tertentu yang sudah dibuat dan di hidden. Untuk tampilan default tampilan menu adalah disembunyikan. Sehingga perlu perintah dengan menekan IC untuk menampilkan menu keterangan dan sifat IC. Hal tersebut dapat dilihat pada Gambar 11.

Setiap IC pada virtual laboratorium teknik digital memiliki karakteristik tersendiri dan dapat dibedakan berdasarkan nomor IC yang terdapat pada bagian atas IC. Terdapat 6 Jenis IC yang disediakan yang berbeda jenis seri dan fungsi dari IC tersebut. Keterangan IC akan muncul apabila titik tengah pada layar ketika menggunakan VR ditekan ketika diarahkan pada IC tersebut. Ketika titik tengah mengenai IC maka titik tengah tersebut akan berubah menjadi sebuah lingkaran yang menunjukkan bahwa IC tersebut siap untuk menerima perintah atau diklik. Setiap kali klik dari setiap IC maka akan muncul tampilan berupa gambar rangkaian, aljabar Boolean, serta tabel kebenaran dari IC tersebut. Setiap IC memiliki tampilan yang berbeda setiap jenisnya. Tampilan tersebut dapat dihilangkan atau dikembalikan kembali dengan cara menekan kembali IC tersebut.

Untuk tampilan Simulator gerbang IC terdapat enam simulator IC yaitu NOT, AND, OR, NAND, NOR, XOR. Algoritma pada IC menggunakan perintah IF Penggunaan algoritma itu digunakan di setiap IC berbeda beda sesuai dengan sifat IC tersebut. Pengaturan masukan nilai 1 dan 0 atau $\mathrm{ON}$ dan OFF dilakukan dengan menekan tombol input pada tampilan dan untuk menghapus tampilan tersebut dengan menekan tombol close warna merah. Pada beberapa simulasi terdapat dua simulasi dalam satu tampilan. Misalkan AND dan OR, untuk mengganti tampilan antara AND dan OR maka harus menekan tombol pada kanan atas sehingga dapat mengubah tampilan dari simulasi yang sudah dibuka.

Pada simulasi gerbang logika pengguna diberikan keleluasaan untuk berinteraksi 
dengan tampilan simulasi tersebut. Tampilan simulasi tersebut dapat terbuka dengan menekan laptop yang terdapat pada meja pada virtual laboratorium teknik digital. Ketika laptop diarahkan titik tengah maka titik tengah tersebut akan berubah menjadi sebuah lingkaran dan akan muncul simulasi dari gerbang jenis apa yang dapat dibuka pada laptop tersebut.

Terdapat empat laptop pada virtual laboratorium teknik digital. Masing-masing laptop menampilkan Gerbang NOT, Gerbang AND/OR, Gerbang NAND/NOR, dan Gerbang $\mathrm{X}$-OR. Pengguna dapat memilih gerbang logika yang ada pada satu laptop yang terdapat dua jenis gerbang. Pada simulasi gerbang logika ini pengguna dapat mengubah masukan dari setiap masukan gerbang logika dan otomatis akan muncul keluaran dari hasil logika dari gerbang logika tersebut. Pengguna juga dapat mengganti gerbang logika yang dengan jenis yang berbeda pada laptop tertentu yang memberikan pilihan dari gerbang logika. Untuk menutup simulasi gerbang logika tersebut dapat dilakukan dengan mengarahkan titik tengah pada virtual laboratorium teknik digital menuju tanda merah yang berada di pojok kanan bawah. Apabila titik tengah sudah mendekati atau mencapai warna merah tersebut maka titik tengah akan berubah menjadi lingkaran dan siap untuk ditutup atau disembunyikan lagi.

Pada simulasi rangkaian digital terdapat sembilan jenis rangkaian simulasi teknik digital yang dapat dicoba dan dipraktikkan. Rangkaian tersebut memiliki fungsi dan hasil yang berbeda sesuai masukan masing-masing rangkaian. Setiap rangkaian memiliki algoritma yang berbeda dan diprogram sesuai dengan rangkaian dan gerbang logika yang digunakan. Rangkaian juga dapat dihitung secara manual menggunakan aljabar Boolean karena pada bagian kanan atas di setiap simulasi rangkaian digital terdapat nilai aljabar Boolean dari rangkaian tersebut. Setiap komputer memiliki simulasi rangkaian teknik digital yang berbeda dan secara acak. Pada komputer-komputer tersebut juga terdapat masukan yang berbedabeda sehingga pengguna dapat memilih rangkaian mana untuk dicoba.

Simulasi rangkaian digital ini mengimplementasikan gabungan dari berbagai gerbang logika sehingga menghasilkan suatu rangkaian logika baru yang lebih rumit. Simulasi rangkaian digital juga terdapat fungsi perhitungan rangkaian dalam bentuk aljabar Boolean. Hal tersebut dapat mempermudah dalam mengidentifikasi rangkaian tersebut dan mengetahui hasil dari rangkaian tersebut dengan mudah. Pengguna diberikan kebebasan untuk mengisi masukan dari rangkaian digital tersebut pada virtual laboratorium teknik digital. Pengguna hanya perlu mengarahkan titik tengah pada titik masukan dan menekan tombol OK atau menyentuh layar, maka masukan akan berubah antara 0 atau 1. Apabila input sesuai dengan fungsi rangkaian maka output akan otomatis berubah menjadi nilai 1 .

Pada setiap simulasi baik simulasi gerbang logika maupun simulasi rangkaian digital. Diperlukan bantuan pengguna dalam mengoperasikan simulasi tersebut. Pengguna hanya perlu memberikan masukan nilai antara 0 atau 1 dengan cara mengarahkan titik tengah pada setiap titik masukan dari rangkaian simulasi dan menekan tombol $\mathrm{OK}$ atau menyentuh layar. Setiap pengguna dapat memberikan masukan yang berbeda sesuai dengan kemauan untuk mengetahui bagaimana fungsi dari gerbang logika tersebut. Pengguna dapat menutup semua tampilan pada simulasi dengan cara menekan tanda merah di bagian bawah sehingga pengguna dapat beralih ke simulasi lain tanpa terhalang pandangan dengan simulasi yang sebelumnya.

\section{SIMPULAN}

Virtual laboratorium teknik digital menggunakan teknologi Virtual Reality untuk meningkatkan kualitas tampilan dan memanfaatkan kemajuan teknologi. Penggunaan virtual laboratorium menggunakan perangkat smartphone android 
untuk membuka aplikasi virtual laboratorium. Perangkat pendukung yang digunakan adalah VR Box dan VR controller yang digunakan sebagai pengendali dari virtual laboratorium. Dalam virtual laboratorium terdapat berbagai barang yang menyerupai barang asli, beberapa barang memiliki fungsi perintah tertentu yang dapat digunakan dan dapat menampilkan suatu tampilan tertentu. Pengembangan virtual laboratorium menggunakan perangkat Unity3D dan dapat dikembangkan lagi lebih jauh. Virtual laboratory memberikan pengetahuan tentang dasar teknik digital berupa karakteristik IC, simulasi Gerbang Logika, dan simulasi rangkaian digital.

Virtual laboratorium teknik digital memiliki berbagai fungsi interaktif yang terdapat dalam penggunaan virtual laboratorium, selain menampilkan teori dari setiap IC gerbang logika. Logika yang digunakan pada simulasi sama dengan logika yang digunakan pada gerbang logika dengan sifat-sifat yang sesuai dengan gerbang logika. Perangkat VR dengan menggunakan Unity3D juga dibuat dengan menyematkan fasilitas kemudahan akses pada virtual laboratorium sesuai dengan kebutuhan. Virtual laboratorium teknik digital juga dapat menghemat biaya apabila terdapat penambahan peralatan dan komponen dari virtual laboratorium.

\section{DAFTAR RUJUKAN}

Almarshoud, A, F. (2011). The advancement in using remote laboratories in electrical engineering education: a review. European Journal of Engineering Education, Vol. 35(5). 425-433. J. Clerk Maxwell, A Treatise on Electricity and Magnetism, 3rd ed., vol. 2. Oxford: Clarendon, 1892, pp.68 - 73.

Dyrberg, N, R., Treusch, A, H., \& Wiegand, C. (2016). Virtual laboratories in science education: Students Motivation and Experiences in Two Tertiary Biology Courses. Journal of Biological Education. Vol.51 (4), 358 - 374.
Jaya, H. (2010). Laboratorium Virtual Mata Kuliah Praktikum Elektronika Digital: Jurusan Pendidikan Teknik Elektronika Fakultas Teknik Universitas Negeri Makassar. Jurnal Elektronika Telekomunikasi \& Computer, Vol. 4(2). 699 - 710 .

Lixia, Z. \& Guangran, L. (2009). Study and Design of 3D Virtual Scenes of Virtual Laboratory. International Conference on Computational Intelligence and Security, 11 - 14 December 2009, Beijing, China.

Mekonnen, E. (2004). Health Laboratory Management and Quality Assurance. Ethiopia: Gondar University College.K. Elissa, "Title of paper if known," unpublished.

Odeh, S., Shanab, S, A., \& Anabtawi, M. (2015). Augmented Reality Internet Labs versus its Traditional and Virtual Equivalence. International Journal of Emerging Technologies in Learning. Vol. 10 (Issue 3), 4 - 9.

Ogungbenro, O, U., Chukwudebe, G, A., Opara, F, K., \& Ezeh, G, N. (2017). Design and Implementation of Logic Gate Emulator. 3rd International Conference on Electro - Technology for National Development, 7 - 10 November 2017, Owerri, Nigeria.

Persson, V. \& Nouri, J. (2018) A Systematic Review of Second Language Learning with Mobile Technologies. International Journal of Emerging Technologies in Learning. Vol. 13 (2), 53 - 61.

WHO. (2011). Laboratory Quality Management System. France: WHO.

Zhang, M., Zhang, Z., Chang, Y., Aziz, E., \& Chassapis, C. (2018). Recent Developments in Game-Based Virtual Reality Educational Laboratories Using the Microsoft Kinect. International Journal of Emerging Technologies in Learning. Vol. 13(1), $138-159$. 